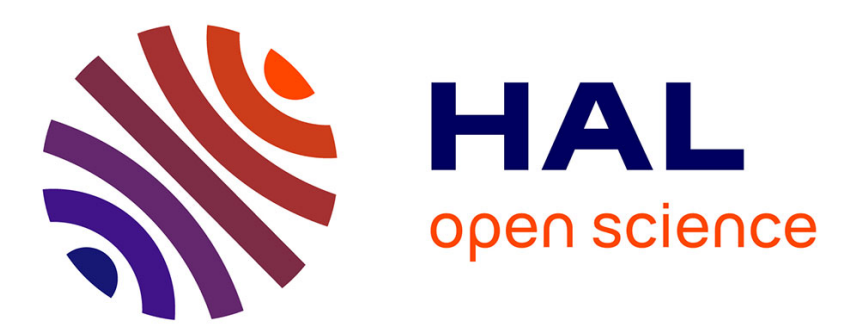

\title{
Correlation between Losses, Complex Permeability and Electron Diffusion in Power Ferrites
}

\author{
H. Meuche, M. Esguerra
}

\section{To cite this version:}

H. Meuche, M. Esguerra. Correlation between Losses, Complex Permeability and Electron Diffusion in Power Ferrites. Journal de Physique IV Proceedings, 1997, 07 (C1), pp.C1-95-C1-98. 10.1051/jp4:1997127 . jpa-00254981

\section{HAL Id: jpa-00254981 https://hal.science/jpa-00254981}

Submitted on 1 Jan 1997

HAL is a multi-disciplinary open access archive for the deposit and dissemination of scientific research documents, whether they are published or not. The documents may come from teaching and research institutions in France or abroad, or from public or private research centers.
L'archive ouverte pluridisciplinaire HAL, est destinée au dépôt et à la diffusion de documents scientifiques de niveau recherche, publiés ou non, émanant des établissements d'enseignement et de recherche français ou étrangers, des laboratoires publics ou privés. 


\title{
Correlation between Losses, Complex Permeability and Electron Diffusion in Power Ferrites
}

\author{
H. Meuche and M. Esguerra
}

Siemens Matsushita Components GmbH \& Co KG, S+M FER M KE, P.O. Box 801709, 81617 Munich, Germany

\begin{abstract}
The contribution of electron diffusion to power losses was studied. From the frequency dependence of complex permeability, the damping and resonance parameters were determined in the frame of the forced oscillator model. The damping constant correlates well with the difference between total and hysteresis losses. The complex permeability, the loss factor and the conductivity were measured as a function of frequency between $80 \mathrm{~K}$ and $300 \mathrm{~K}$. From the $\tan \delta$ - maximum over temperature for different frequencies an activation energy was calculated. Its value agrees with the activation energy for the conductivity, showing a clear correlation between $\tan \delta$ and electron diffusion for power materials.

In an attempt to influence the electron diffusion-driven magnetic behavior, electric fields perpendicular to the magnetic flux were applied to ring cores. The dependence of magnetic properties on electric fields as a function of temperature, frequency, amplitude and phase shift between magnetic and electric fields was measured. A dramatic effect on power losses in dependence of field direction was observed, showing a maximum at the temperature of the secondary permeability maximum.
\end{abstract}

\section{INTRODUCTION}

To reduce power losses in ferrites, knowledge about their origin is necessary. This work presents new aspects in the study of power loss mechanisms. Power losses are commonly separated into hysteresis losses, (classical) eddy current losses and residual losses [1]. Eddy currents are considered in a macroscopic way, i. e. taking the sample dimensions and resistivity into account. For ferrite cores of usual size $(\leq 100 \mathrm{~mm}$ ) this contribution is of only minor importance, since power ferrites have large resistivity value (>1 $\Omega \mathrm{m}$ ). For the purpose of this paper, classic eddy current losses will be neglected. One part of the residual losses is the frequency dependent losses due to damping of domain walls, which after Wijn [2] is mainly due to electron diffusion. Gradzki [3] claims that residual losses are related to the electric field caused by domain wall motion via spin polaron interaction. In order to influence this process and effect domain wall damping, an electric field perpendicular to the magnetic field and with the same frequency was applied to ring cores.

\section{EXPERIMENTAL}

\section{1 Sample Preparation and Characterization}

Different Mn-Zn ferrites ring cores samples R20 and R29 in different materials were used [4]. In order to apply an electric field perpendicular to the magnetic flux, the samples were metallized with copper on the pole surface with electric contacts as showed in figure 1. The DC-resistance is also measured using these contacts with a multimeter (Keithley 2001) in four wire technique. Measurements of the complex permeability over frequency were carried out with an impedance analyzer (Hewlett Packard 4194A with impedance probe), having the possibility to trigger an external generator for a second phase coupled signal. Dynamic hysteresis loops were measured by a 16 bit digital oscilloscope (Tektronix 744A) and a current probe [5]. Loss power measurements were made with a VAW-meter (Clarke \& Hess 258) [6]. In the range from $80 \mathrm{~K}$ to $300 \mathrm{~K}$ the temperature was varied in a liquid nitrogen cryostat and from room temperature to $130^{\circ} \mathrm{C}$ in a temperature chamber.

\section{2 Superposition of an electric field}

One possibility to superpose an electric field is to connect the winding and the electric contacts in parallel. However, the resulting amplitude and the relative phase are then fixed. In order to overcome this limitation it is necessary to use a second signal source, phase coupled to the first signal. The impedance analyzer triggers an external function generator (Wavetek 
90). Both the generator trigger input and the impedance probe are connected to the single signal output of the analyzer (figure 2). With this experimental setup it is possible to trigger the generator phase coupled to the magnetizing voltage from without influencing the measurement. The amplitude and the phase shift to the magnetizing voltage of the electric field can then be freely got. The same principle is used for hysteresis and power loss measurements: one function generator is the source for the flux density and triggers the second one giving rise to the electric field.

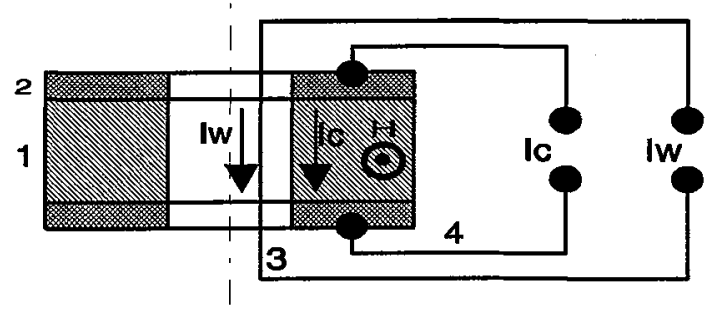

1: ferrite ring core

2: metallization

3: winding

4: electrical contacts

Iw: current flowing in the winding Ic: current flowing in the core material $\mathrm{H}$ : magnetic field strength

Figure 1: Ring core with metallization

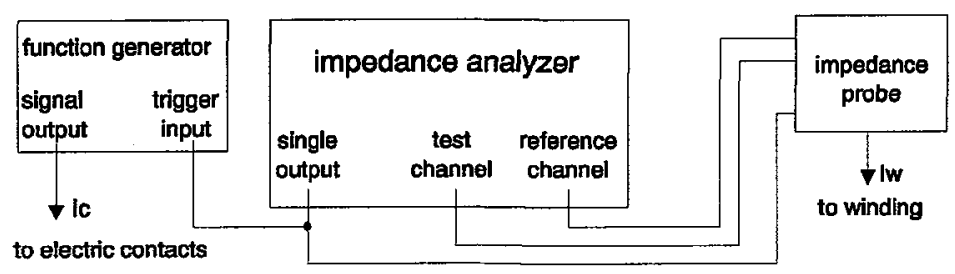

Figure 2: Experimental setup for electric field synchronization

\section{CORRELATION BETWEEN LOSSES, DAMPING AND ELECTRON DIFEUSION}

If the damping of domain walls contributes to the frequency dependent power losses, there must be a correlation between the damping constant and the difference between total and hysteresis losses. The complex permeability over frequency and power losses at different frequencies ( $f=25 \mathrm{kHz}, 200 \mathrm{kHz}$ and $500 \mathrm{kHz}$ ) were measured at $\mathrm{T}=80^{\circ} \mathrm{C}$, i. e. close to the core loss minimum, for power ferrites with different calcium additions. The damping ratio $2 \lambda / \omega_{0}, \lambda$ being the damping constant and $\omega_{0}$ the resonance frequency, was determined in the frame of the forced oscillator model from the $\mu$ ' $(\omega)$ - curve [7]. Figure 3 shows the searched correlation between the damping ratio and the difference between total and hysteresis losses.

Wijn [2] claims electron diffusion is the cause for domain wall damping. The activation energy $E_{\mathrm{A}}$ was calculated from the $\tan \delta$-maximum over temperature for different frequencies and from DC-resistance over temperature (figure 4) on sample R20/N27 [8],[9]. Since these two activation energies $\left(E_{A}(\tan \delta)=21 \mathrm{meV} \pm 2 \mathrm{meV}, E_{A}(\rho)=23 \mathrm{meV} \pm 2 \mathrm{meV}\right)$ are almost equal it can be followed that electron diffusion plays a role in domain wall damping for power ferrites. Moreover it was found, that the damping ratio $2 \lambda / \omega_{0}$ also has a maximum over temperature in the same temperature region as the tan $\delta$ maximum [10].

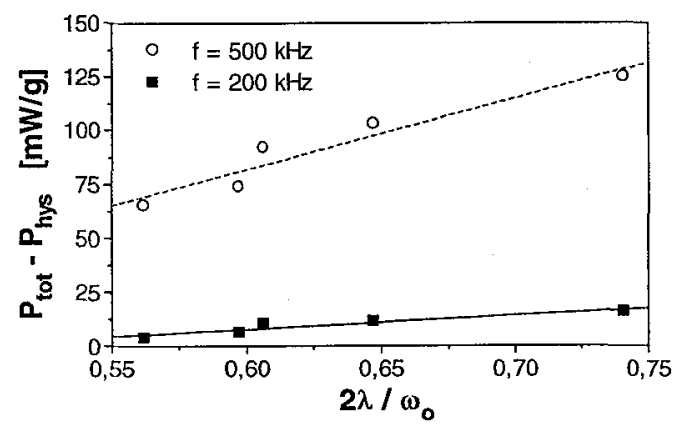

Figure 3: Correlation between the damping ratio and power loss, $\mathrm{T}=80^{\circ} \mathrm{C}$ and $\mathrm{B}=50 \mathrm{mT}$, different $\mathrm{R} 29 / \mathrm{N} 27$

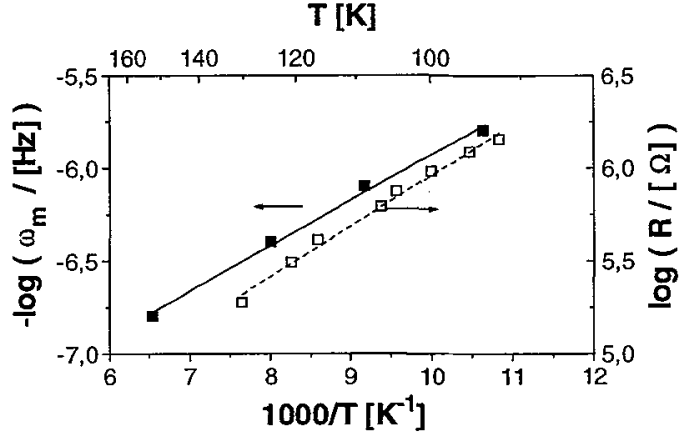

Figure 4: Determination of activation energy, R20/N27 (for $\tan \delta$ measurement $\mathrm{B}<0.5 \mathrm{mT}$ ) 


\section{INFLUENCE OF MAGNETIC PROPERTIES BY AN ELECTRICAL AC-FIELD}

To influence the electron diffusion, electric fields perpendicular to the magnetic flux were applied to the samples. If there is an interaction with the domain walls affecting its damping, then changes in the complex permeability over frequency should be observed. The complex permeability was measured at room temperature for the core R20/N27 at low flux density (B $<0.5$ $\mathrm{mT}$ ), with two different phase shifts $0^{\circ}$ and $180^{\circ}$ between the electric field (current $\mathrm{Ic}=30 \mathrm{~mA}$ ) and the magnetizing voltage as well as without electric field (s. figures 5 and 6 ). The current Ic rather than the field amplitude $\mathrm{E}$ has been held constant, since it was observed that the relative variation at a fixed frequency is proportional to Ic. Both changes in the ratio of maximum permeability to initial permeability $\mu_{\max }^{\prime} / \mu_{\mathrm{i}}$, which is related to $2 \lambda / \omega_{0}[6]$, and changes in resonance frequency $\omega_{0}$ have been observed.

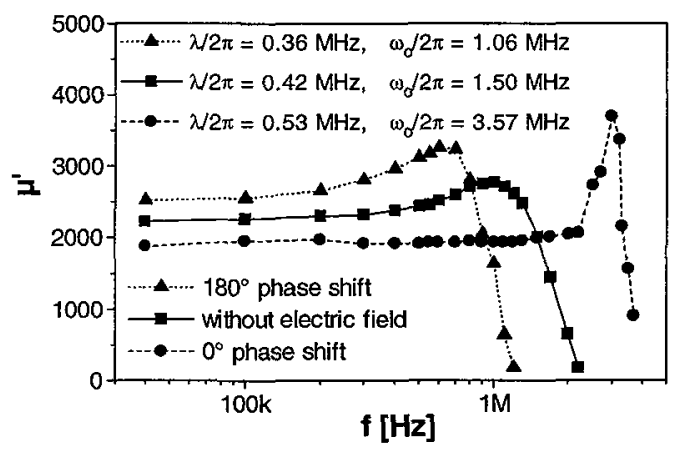

Figure 5: Real part of complex permeability $\mu^{\prime}$ (f) at room temperature, $\mathrm{B}<0.5 \mathrm{mT}, \mathrm{Ic}=30 \mathrm{~mA}, \mathrm{R} 20 / \mathrm{N} 27$

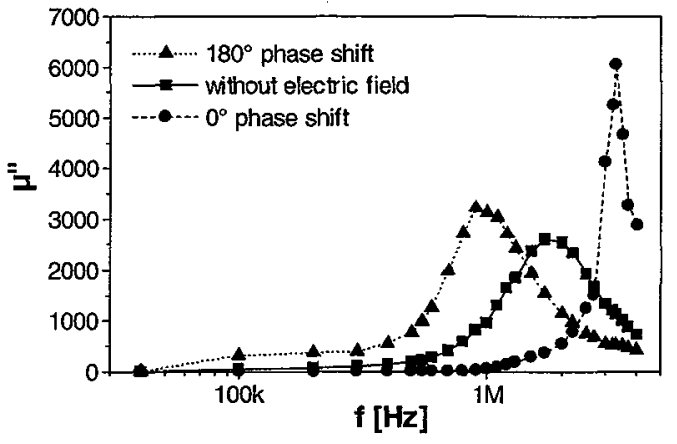

Figure 6: Imaginary part of complex permeability $\mu$ ''(f) at room temperature, $\mathrm{B}<0.5 \mathrm{mT}$, Ic $=30 \mathrm{~mA}, \mathrm{R} 20 / \mathrm{N} 27$

Changes in the damping of the domain wall motion should be also seen in the power loss. Power losses were measured at a flux density $\mathrm{B}=25 \mathrm{mT}$ for different frequencies as a function of the current Ic in the core at $0^{\circ}$ and $180^{\circ}$ phase shift on R20/N27 at room temperature (Figure 7). The variation of the power losses increase with increasing the current Ic and higher frequencies. Losses decrease when the phase shift is $0^{\circ}$ and increase if it is $180^{\circ}$ phase shift.

Hysteresis measurements were performed on a sample R20/T38 with a lower resitivity $(\rho \approx 0.1 \Omega \mathrm{m})$ in order to achieve a larger current Ic at a frequency $\mathrm{f}=10 \mathrm{kHz}$ both without and with electric field and with a phase shift of $0^{\circ}$ and $180^{\circ}$ at room temperature (Figure 8). The electric field changes the width of the loops without affecting the saturation flux density. At $0^{\circ}$ phase shift the coercive force decreases and at $180^{\circ}$ phase shift increases in correlation with the power loss behaviour.

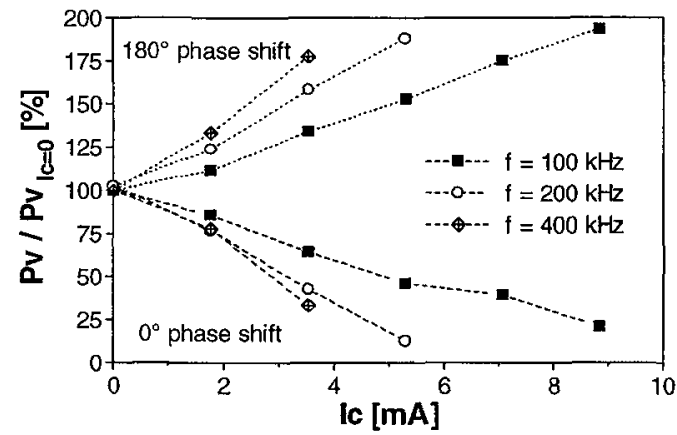

Figure 7: Changes in power loss as function of core current at room temperature, $\mathrm{B}=25 \mathrm{mT}, \mathrm{R} 20 / \mathrm{N} 27$

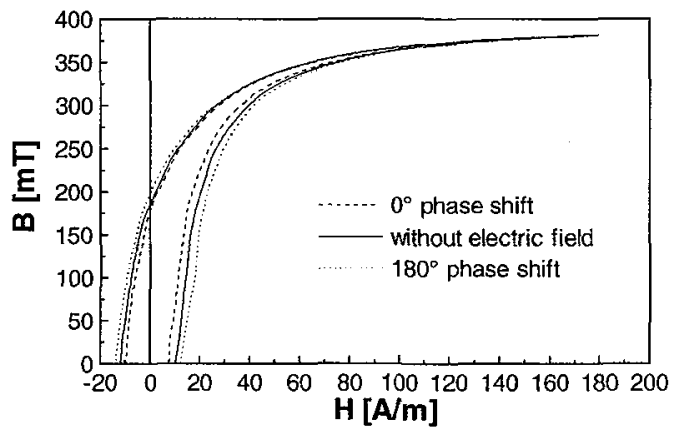

Figure 8: Hysteresis loop with electric field at room temperature, $\mathrm{f}=10 \mathrm{kHz}, \mathrm{Ic}=180 \mathrm{~mA}, \mathrm{R} 20 / \mathrm{T} 38$

Additional measurements of the temperature dependence on a R20/N27 sample in the range from $20{ }^{\circ} \mathrm{C}$ tom $130{ }^{\circ} \mathrm{C}$ of initial permeability $(B<0.5 \mathrm{mT}, \mathrm{Ic}=30 \mathrm{~mA}$, figure 9$)$ and power loss $(B=100 \mathrm{mT}, \mathrm{Ic}=100 \mathrm{~mA}, \mathrm{f}=100 \mathrm{kHz}$, figure 10) both without and with electric field were preformed. 


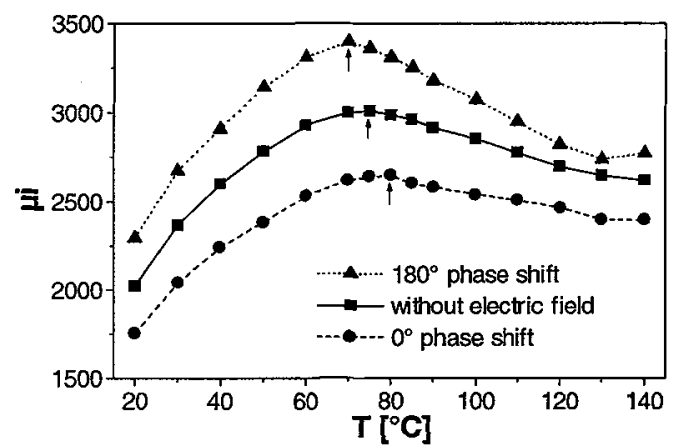

Figure 9: Initial permeability $\mu_{\mathrm{i}}$ over temperature with electric field, $\mathrm{B}<0.5 \mathrm{mT}, \mathrm{f}=100 \mathrm{kHz}, \mathrm{R} 20 / \mathrm{N} 27$ (SPM indicated by arrow)

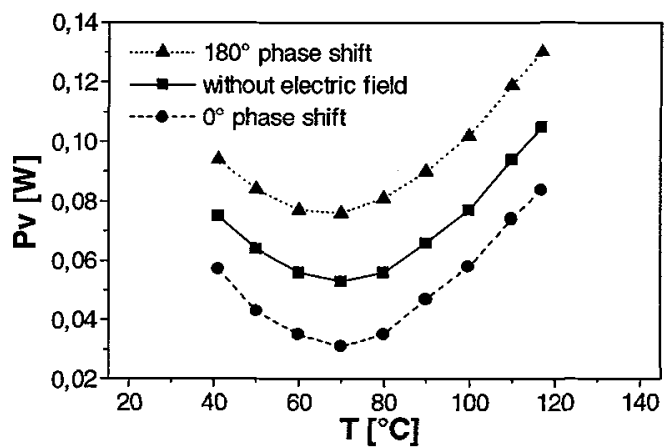

Figure 10: Power loss $\mathrm{Pv}$ over temperature with electric field, $\mathrm{B}=100 \mathrm{mT}, \mathrm{f}=100 \mathrm{kHz}, \mathrm{R} 20 / \mathrm{N} 27$

A strong effect on initial permeability and power loss in dependence of phase was observed, showing a maximum at the temperature of the secondary permeability maximum (SPM). The electric field with $0^{\circ}$ phase shift decreases the initial permeability and the power loss and shifts the SPM to higher temperatures but the electric field with $180^{\circ}$ phase shift increase initial permeability and power loss and shifts the SPM to lower temperatures. The change in power losses is highest at the SPM. Changes in the initial permeability and the displacement of the secondary permeability maximum (SPM) over temperature (figure 9) can be explained by a change in crystal anisotropy since the temperature zero crossing of crystal anisotropy occurs at the SPM [11].

\section{CONCLUSION}

It could be shown that domain wall damping plays an important role in the residual losses of power ferrites. Damping and consequently power losses can be drastically influenced by applying electric fields without affecting the saturation flux density. There is evidently an interaction between the charge carriers building up the current Ic and the moving domain walls [10]. An influence of the current Ic on crystal anisotropy was also observed.

\section{Acknowledgments}

The authors would like to thank Prof. Esquinazi from Leipzig University and Dr. Beer, Dr. Holubarsch and Dr. Bogs from Siemens Matsushita Components Munich for helpful discussions .

\section{References}

[1] Graham C. D., J. Appl. Phys. 11 (1982) 8276-8280

[2] Wijn H. P. J., Magnetic Relaxation and Resonance Phenomena in Ferrites (Dissertation, University of Leiden, 1953) pp. $43 \mathrm{ff}$.

[3] Gradzki P. M., Core loss characterization and design optimization of high-frequency power ferrite devices in power electronics applications ( Dissertation, Virginia Polytechnic Institute and State University, Blacksburg 1992) pp. 54 ff.

[4] Siemens Matsushita Components GmbH \& Co. KG, Data Book, Ferrites and Accessories (1994)

[5] Esguerra M., "Dynamische Messung der Hystereseschleifen von Ferriten bis $100 \mathrm{kHz}$ ", Seminar "Weichmagnetische Ferrite", Technische Akademie Esslingen, March 1993

[6] Hess J., Elektron. J. 28 (1993) 34-36

[7] Esguerra M., "Calculation of Magnetic Losses in Ferrites from Measured Major Loops", First International Workshop on Simulations of Magnetisation Processes, Vienna September 1995, H.Hauser Ed. (TU Wien,Vienna 1996) pp. 29-37

[8] Smit J. and Wijn H. P. J., Ferrites (Philips Technical Libary, Eindhoven 1959) pp. 289 ff.

[9] Krupicka S., Physik der Ferrite und der verwandten magnetischen Oxide, Vieweg-Verlag Braunschweig 1973, pp. $654 \mathrm{ff}$.

[10] Meuche H., Esguerra M. and Esquinazi P., will be published in J. Appl. Phys. (1997)

[11] Stijntjes Th. G. W. and Roelofsma J. J., Advances in Ceramics, 16 (1984) 493-500 